\title{
A preliminary evaluation of the European Non-native Species in Aquaculture Risk Assessment Scheme applied to species listed on Annex IV of the EU Alien Species Regulation
}

\author{
G. H. Copp ${ }^{1, *}$, M. J. Godard ${ }^{1}$, I. C. Russell ${ }^{1}$, E. J. Peeler ${ }^{2}$, F. Gherardi ${ }^{3}$, E. Tricarico ${ }^{3}$, L. Miossec ${ }^{4}$,

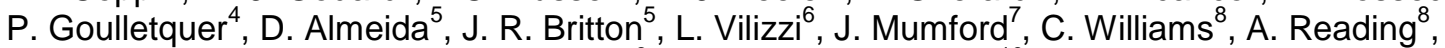 \\ E. M. A. Rees ${ }^{9}$ and R. Merino-Aguirre ${ }^{10^{9}}$
}

\footnotetext{
${ }^{1}$ Salmon and Freshwater Team, Centre for Environment, Fisheries and Aquaculture Science, Lowestoft, UK

2 Epidemiology and Risk Team, Centre for Environment, Fisheries \& Aquaculture Science, Weymouth, UK

${ }^{3}$ Università degli Studi di Firenze, Florence, Italy

${ }^{4}$ Institut français de Recherche sur la Mer (IFREMER), Nantes, France

${ }^{5}$ Centre for Conservation Ecology and Environmental Science, Bournemouth University, Poole, UK

${ }^{6}$ Ichth-Oz Environmental Science Research, Irymple, Vic., Australia

${ }^{7}$ Centre for Environmental Policy, Imperial College London, Ascot, UK

${ }^{8}$ Environment Agency, Brampton, Huntingdon, Cambridgeshire, UK

${ }^{9}$ Environment Agency, Hampshire, UK

${ }^{10}$ Department of Ecology, Complutense University of Madrid, Madrid, Spain
}

*: Corresponding author : Gordon H. Copp, email address : gordon.copp@cefas.co.uk

\begin{abstract}
:
Developed for carrying out risk assessments under the European Commission (EC) Council Regulation No 708/2007 concerning the use of alien and locally absent species in aquaculture (ASR), the European Non-native Species in Aquaculture Risk Assessment Scheme (ENSARS) is briefly summarised, and the 'Organism' module is applied to the 24 species listed in ASR's Annex IV. Four other ENSARS modules (Infectious Agent, Facility, Pathway, and Socio-economic) were used to assess two case study species (European catfish Silurus glanis L. and red swamp crayfish Procambarus clarkii Girard). No Annex IV species was categorised as low risk, 10 as moderately low risk, 12 as medium risk, two as moderately high risk and none as high risk. The results are discussed and recommendations are made on further development of the scheme as well as the need to have multiple assessors of multidisciplinary expertise from the Member States concerned carry out the assessments using an approach similar to that carried out by EU Reference Laboratory proficiency tests.
\end{abstract}

Keywords: aquaculture ; biological invasions; decision support ; ENSARS; EU legislation ; risk analysis 
Aquaculture has a very long history in Europe (Goulletquer \& Héral 1997; Copp et al. 2005), benefiting economically from the use of alien species. This continues to be a fast-growing sector, where innovation and new outlets are being explored. However, invasive alien species have been identified as one of the key causes of loss of native species, harm to bio-diversity (Gherardi \& Acquistapace 2007) as well as negative impacts on aquaculture products (e.g. introduction of exotic pathogens) (Nunan et al. 1998; Ghittino et al. 2003; Secretariat of the Convention on Biological Diversity 2004; Olenin et al. 2008). Moreover, medium-term impacts of alien species might even be higher than currently expected due to the 'invasion debt' since considerable time lags may occur between the date of first introduction and its establishment as part of the regional fauna or flora. Therefore, current patterns of alien-species richness may better reflect historical rather than contemporary human activities (Essl et al. 2011). Therefore, under Article $8(\mathrm{~h})$ of the Convention on Biological Diversity (CBD), contracting parties are required, as far as possible, to prevent the introduction of, control or eradicate those alien species that threaten ecosystems, habitats or species. In balancing these conflicting interests, the European Commission (EC) has identified the need to develop a framework to ensure adequate protection of aquatic habitats from the risks associated with the use of non-native species in aquaculture.

Council Regulation (CR) No 708/2007 of the European Commission (EC) on 11 June 2007 concerning the Use of Alien and Locally-Absent Species in Aquaculture (ECASR) is applicable to all aquatic species except those considered to be 'ornamental' in use (EC 2007). In response to the EC-ASR, and as foreseen under its Article 9, a scheme was developed as part of the EC Coordination Action 'IMPASSE' ('Environmental impacts of alien species in aquaculture', Project No 044142), to provide an environmental risk assessment (RA) in the case of movements categorised as 'non-routine' under these new measures. Non-routine movements are any movement of aquatic organisms that do not fulfil the criteria for routine movement, with the latter defined as "where the movement of aquatic organisms is from a source where there is low risk of transferring non-target organisms and which, on account of the characteristics of the aquatic organisms and/or the method of aquaculture to be used, does not give rise to adverse ecological effects". These protocols are described elsewhere in detail (Copp et al. 2008) and in summary (Copp et al. this issue); they comprise the European Non-native Species in Aquaculture Risk Assessment Scheme (ENSARS), which is modular in structure and based on protocols adapted from broader non-native species risk assessment schemes (Baker et al. 2008; EPPO 2009).

To facilitate the implementation of the EC-ASR whilst avoiding unnecessary regulation of introduced species that have a long history in aquaculture, the EC-ASR includes a list of species (Annex IV) that may be exempted from the Regulation due primarily to their well-established economic importance. However, the EC-ASR allows Member States the option to impose controls under the EC-ASR and to disregard the Annex IV (exemption) status of any species on that list, for example for a species that has not previously been used in aquaculture in the Member State concerned.

In principle, species initially included in Annex IV of the EC-ASR, as well as those added subsequently (EC 2008), should comply with two criteria: 1) the species has been used for an extended period in aquaculture (defined as a minimum of 50 generations), and 2) the species has not been found to exert adverse impacts on native species or ecosystems. In practice, few of the species included in the initial and revised Annex IV comply with the second criterion, and several of the species are not in widespread use across the EU. In light of this, and to help inform decisions 
on the extent to which it might be necessary to retain controls on Annex IV species, UK authorities decided to have risk assessments carried out on all species listed in Part A of the revised Annex IV (henceforth Annex IV species), given that those in Part B are relevant to French overseas departments only (European Commission 2008). The aim of the present study was to trial the ENSARS scheme (summarized in Copp et al. this issue) on Annex IV species using the Organism Module, with other modules of the scheme trialled on two species as case studies: the European catfish Silurus glanis (L., 1758), which is listed in Annex IV, and red-swamp crayfish Procambarus clarkii Girard, 1852, which does not meet either of the two criteria for inclusion in Annex IV and has been categorised in a risk screening assessment as posing a high risk of being invasive (Tricarico et al. 2009).

\section{Methodology}

The ENSARS scheme is based on the Great Britain (GB) Non-native Species Risk Assessment scheme (Baker et al. 2008; Mumford et al. 2010), which, in turn, has its origins in the Decision-Support Scheme for Quarantine Pests developed by the European and Mediterranean Plant Protection Organisation (EPPO 2011). As such, the ENSARS is modular in structure, which is described in detail in Copp et al. (2008) and summarised in Copp et al. (this issue), and consists of seven assessment modules with which to evaluate invasiveness potential and then in greater detail the various risks potentially associated with the use of any non-native aquatic organism (and those associated thereof) in aquaculture. ENSARS includes assessments of the risks of escape, of introduction to and establishment in open waters via transport pathways, of rearing facilities, of the transmission of non-target infectious agents, as well as potential ecosystem and socio-economic impacts (see Fig. 1 in Copp et al. this issue).

To initiate an assessment, a risk assessment area is defined, and the type of assessments required (i.e. the modules to be used) are identified in the Entry Module. In the assessment modules, each question requires the assessor to provide a response, a justification for the response and a self-assessment of the confidence level they place on their response (i.e. reflecting the available evidence upon which the response was formulated). Each module requires specialist expertise and can be used independently, though some questions in the Organism Module are best answered using the outcomes of other modules (e.g. those relating specifically to Infectious Agents, Socio-Economics, or Pathways). Therefore, a multi-disciplinary team is normally required to carry out the assessments comprehensively, but in some cases this may not be possible and responses (and confidence levels) should reflect the fact that the assessment was completed by a non-specialist. A concluding module was developed to summarize and formulate management options for mitigating the risks (see Fig. 1 in Copp et al. this issue).

All species were assessed using the Organism Module, complemented in assessments the case study species (see below) by outputs from the Infectious Agent, Facility, Pathway and Socio-economic modules. The Entry, Pre-screening and Risk Summary and Risk management modules were not used in the present study because all species examined (except red-swamp crayfish) are listed in Annex IV and therefore pre-selected. The Annex IV species included 22 fin fishes and two marine molluscs (Table 1). The fin fishes were assessed by UK-based assessors with the entire UK as the risk assessment area, whereas the two mollusc species where assessed by France-based assessors, with metropolitan France as the risk assessment area. To trial the entire scheme, the two case study species (European catfish, red-swamp crayfish) were also assessed with the Infectious Agent, Facility, Pathway and Socio-economic modules. The red-swamp crayfish was assessed by 
Italy-based assessors, with Italy as the risk assessment area. This species was selected as an example of a non-Annex IV species because of its exploitation in fisheries and its potential for multiple environmental impacts, including transmission of the crayfish plague to European native crayfishes.

Each module comprises different sections to assess particular risks (see Tables 1 and 2). Thus, for example, the Organism Module includes sections on introduction, establishment, dispersal and impact (Table 1). The scores for the risks at each section range between 0 and 4 . Risk categories for the overall mean per module and per species use the same score intervals ('[' indicates closed interval; ']' indicates open interval): [0-0.8[ for low risk; [0.8-1.6[ for moderately low risk; [1.6-2.4[ for medium risk; [2.4-3.2[ for moderately high risk; [3.2-4.0] for high risk. Confidence levels are attributed to each response $(0=$ low, $1=$ moderate, $2=$ high, $3=$ very high confidence) from which an overall mean confidence score is derived.

\section{Results}

Based on the overall means scores and subsequent risk categories for the Organism Module, none of the 24 species were categorized as low risk, 10 as moderately low risk, 12 as medium risk, two as moderately high risk and none as high risk (Table 1). The highest scoring species was common carp Cyprinus carpio, followed by goldfish Carassius auratus (the two species categorized as moderately high risk). The two mollusc species, i.e. Pacific cupped oyster Crassostrea gigas and Japanese clam Ruditapes philippinarum, each had similar scores and were categorized as medium risk. The two lowest scoring (moderately low risk) species were beluga sturgeon Huso huso and fringebarbel sturgeon Acipenser nudiventris (Table 1). For the 'Risk of Introduction' section of the Organism module, African catfish Clarias gariepinus was attributed the highest score, followed by Japanese clam and common carp. The highest scores for the sections on risks of establishment, dispersal and impact were attributed to common carp and goldfish. Regarding the non-Annex species, red swamp-crayfish was categorized as moderately high risk, encompassing high scores for the four sections, in particular for the risks of dispersal and impact, with the highest scores on all species (Table 1).

On the overall means of the Organism Module, the highest confidence level was for common carp, followed by Japanese clam and Pacific cupped oyster (Table 1). These three species achieved the highest values in each section. Red-swamp crayfish showed an overall high confidence level, with the highest confidence scores of all species for the risks of establishment and impact (Table 1).

In further assessments of the two case study species using the Infectious Agent Module, red-swamp crayfish attracted a higher risk ranking (medium) than European catfish (moderately low) despite the discovery in latter of an ancyrocephalid monogenean parasite Thaparocleidus vistulensis (Sivak, 1932), a novel species for the UK. Red-swamp crayfish attracted elevated mean scores for all sections but especially for risks of dispersal, with a score twice that for European catfish (Table 2a). Assessor confidence levels for Infectious Agent assessments were generally similar for European catfish and red-swamp crayfish except for the risks of dispersing infectious agents for which confidence was lower for European catfish than redswamp crayfish (Table 2a).

In the Facility Module, both European catfish and red-swamp crayfish were categorized overall as medium risk, with the highest mean scores being associated with the risks of releasing non-target organisms (Table 2b). However, confidence in 
the assessments of red-swamp crayfish was low for all sections, contrasting the moderate confidence in the responses for European catfish in this module.

Using the Pathway Module, European catfish was categorised as moderately high risk, which contrasts a medium risk ranking for red-swamp crayfish, mainly due to risks associated with destination use for European catfish (Table 2c). Confidence levels in the responses for European catfish were also higher than for the red-swamp crayfish assessment, with the greatest confidence in responses related to destination use.

Using the Socio-economic Module, European catfish was categorized overall as being of moderately low risk, with the eradication costs section attracting the highest mean risk score. This contrasted with the lower eradication cost score for red-swamp crayfish, which attracted a risk score for market impact (see Copp et al. this issue) that was almost $3 \times$ higher than that attributed to European catfish, resulting in an overall 'medium' ranking for socio-economic risks (Table 2d). Similar to the Pathway Module assessments, confidence levels in the assessment of socio-economic risks were higher for European catfish than for red-swamp crayfish, with the lowest confidence being in response to questions related to the eradication costs for redswamp crayfish (Table $2 \mathrm{~d}$ ).

\section{Discussion}

Although common carp and goldfish are considered as 'naturalized' (i.e. introduced and established a long time ago) in many European countries, these species were assessed as posing moderately high risks to native species and ecosystems. Indeed, these two species have attracted amongst the highest risk scores as potentially invasive both in Europe (Britton et al. 2010; Clavero 2011; Almeida et al. 2013; Puntila et al. 2013; Tarkan et al. 2014) and elsewhere (Onikura et al. 2011; Troca \& Vieira 2012; Vilizzi \& Copp 2013; Tarkan et al. 2014). This high risk categorisation by scientific assessors derives mainly from the capacity of these cyprinid species as ecosystem engineers to modify habitats (increasing turbidity, uprooting vegetation) such as experienced with common carp in various locations world-wide (review in Weber \& Brown 2009). The capacity of common carp and goldfish to colonise and reach levels of abundance that can significantly alter habitat varies considerably across Europe, and indeed world-wide.

The overall risk scored attributed to common carp was similar to that of red-swamp crayfish, another well-known ecosystem engineer (Gherardi \& Acquistapace 2007), which was not included in Annex IV because it does not meet the first criterion (i.e. extended period of use in aquaculture). Conversely, the sturgeons and their hybrids were ranked moderately low-to-medium risk, which reflects the absence of any evidence of these species establishing self-sustaining populations outside their native ranges. Indeed, there is growing evidence of declines in some sturgeon populations in their native ranges, which requires consideration when balancing the low-to-medium ranking of sturgeons with conservation efforts to sustain and protect endangered native sturgeons. Some other Annex IV species were classed as moderately high risk of introduction (e.g. African catfish and Japanese clam), which may justify their inclusion in a 'watch list' (Clavero 2011; Almeida et al. 2013) as potential new invaders of climatically suitable areas within Europe where they do not yet exist.

The detection of $T$. vistulensis represents a new parasite record for the British Isles (Reading et al. 2012), apparently introduced and disseminated with the movement of European catfish. Owing to the limited number of parasitological examinations 
conducted on this fish species, it remains feasible that the parasite is common in the gills of this fish and has long been established in Britain. This parasite had been reported in European catfish previously from different regions (Copp et al. 2009), with detailed information provided by Mihálik (1982). There is a lack of detailed information on the distribution, surveillance, control and impact of the parasite in its native range. This limited information on many aspects of the biology of $T$. vistulensis prevents a comprehensive assessment of future spread and disease risk, and this is reflected in the confidence level that accompanies some of the answers given in the Infectious Agent Module, in particular the section on dispersal. Lack of information is likely to be a common issue, as many non-native fish parasites have received little or no study. The likelihood that an introduced parasite switches host is a key consideration (Peeler et al. 2010), and therefore the strict host specificity of $T$. vistulensis for siluriform fish (Lim et al. 2001) supports the likelihood of low disease risk to native fishes in England and Wales. Blanc (1997) listed a number of ancyrocephalid monogenea in a table of introduced fish pathogens. However, there is no evidence or published literature to suggest that $T$. vistulensis is an important pathogen of free-living fishes. Other novel pathogens of European catfish exist (Lorincz et al. 2012), but these have not been included in this example assessment, which demonstrates the potential role of non-native European catfish as a disease vector. Regarding the red-swamp crayfish, the overall risk of this species was higher than that of the European catfish, due mainly to the risks of dispersal and impact of the crayfish plague (Aquiloni et al. 2010) and the fungal pathogen Batrachochytrium dendrobatidis that causes lethal skin infections (chytridiomycosis) in amphibian species world-wide (McMahon et al. 2013).

Outcomes of the Facility and Pathway modules emphasize the need for proper controls, and surveillance measures should be imposed during the importation, transport and use of non-native species at the aquaculture facilities to avoid future accidental introductions of undesirable species (e.g. Beyer 2004). In different sections of these two modules, destination use was the key factor in the higher risk ranking of European catfish relative to red-swamp crayfish (medium risk), and this may be attributed to the increasing sport fishing interest in this large fish (Britton et al. 2010), which increases the likelihood of unauthorised intentional releases. In the Socio-economic Module, the European catfish was found to pose relatively low risk; this contrasts the red-swamp crayfish, which is known to damage river banks and agricultural fields through their burrowing activity (Barbaresi et al. 2004).

Confidence in the responses was high for some species, reflecting the level of knowledge from published literature either on their invasion histories in Europe, such as common carp (Balon 2004) and the red-swamp crayfish (Gherardi et al. 1999; Aquiloni et al. 2010), or their extensive use in aquaculture, e.g. common carp, European catfish (Copp et al. 2009) and the two mollusc species (Fisheries and Aquaculture Department of FAO, accessed on 17/02/2013). Confidence levels were rated as moderate for other species on the list (Table 1) and low for red-swamp crayfish in the Facility Module because this species is mainly exploited as capture fisheries rather than as a cultured organism (E. Tricarico, pers. obs.).

In conclusion, the outcome of these preliminary assessments demonstrates that some of the species included in Annex IV of the EC-ASR clearly do not comply with the second criterion for inclusion on the list (no adverse environmental impacts), although such impacts may be 'tolerated' by authorities in countries where a species has a long history of use in aquaculture. In those countries where the species has not previously been used, or it has a short history of use, such concerns need to be recognised and taken into account by the relevant authorities as part of the risk management process, in particular when making decisions about the future use of the species, balancing the outcome of the risk assessments (of potential adverse impacts) against the potential economic benefits. This might eventually prompt the 
managers to recommend additional options such as the use of sterile strains if the associated risks were being too high. Overall, flexibility in the decision-making process is important to develop effective management strategies, especially to address the risks of non-native species across a large and/or varied geographic area whilst incorporating specific conservation projects at a regional level. The variability in the confidence levels highlights the need for developing a greater understanding of virtually all aspects associated with the use of non-native species in aquaculture. Further methodological developments should also be considered: it might be of interest to test how the overall results will be improved by (1) increasing the number of assessors, (2) a multi-disciplinary expertise from the countries concerned, including the regional scale, using an approach similar to that carried out by EU reference laboratory (EURL) proficiency tests. Implementation of a comparative approach with other assessment methods such as BINPAS/BPL (Narscius et al. 2012) or modeling (Gallien et al. 2010) would also be useful to test the overall consistency of the assessment outcomes.

\section{Acknowledgements}

This paper is dedicated to the memory of our dear friend and co-author, Prof. Francesca Gherardi, who passed away before this paper was submitted for publication. Funding was provided principally by the European Commission (Project: IMPASSE), with contributions from the UK Department of Environment, Food and Rural Affairs. D. Almeida holds a post-doctoral grant from the European Commission (Marie Curie Action, FP7-PEOPLE-2011-IEF).

\section{References}

Almeida D., Ribeiro F., Leunda P.A., Vilizzi, L. \& Copp G.H. (2013) Effectiveness of an invasiveness screening tool for non-native freshwater fishes (FISK) to perform risk identification assessments in the Iberian Peninsula. Risk Analysis 33, 14041413.

Aquiloni L., Tricarico E. \& Gherardi F. (2010) Crayfish in Italy: distribution, threats and management. International Aquatic Research 2, 1-14.

Baker R.H.A., Black R., Copp G.H., Haysom K.A., Hulme P.E., Thomas M.B., Brown A., Brown M., Cannon R.J.C., Ellis J., Ellis M., Ferris R., Glaves P., Gozlan R.E., Holt J., Howe L., Knight J.D., MacLeod A., Moore N.P., Mumford J.D., Murphy S.T., Parrott D., Sansford C.E., Smith G.C., St-Hilaire S. \& Ward N.L. (2008) The UK risk assessment scheme for all non-native species. In: W. Rabitsch, F. Essl \& F. Klingenstein (eds) Biological Invasions - from Ecology to Conservation. Neobiota 7 (2008): 46-57.

Balon E.K. (2004) About the oldest domesticates among fishes. Journal of Fish Biology 65, 1-27.

Barbaresi S., Tricarico E. \& Gherardi F. (2004) Factors inducing the intense burrowing activity of the red-swamp crayfish, Procambarus clarkii, an invasive species. Naturwissenschaften 91, 342-345.

Beyer K. (2004) Escapees of potentially invasive fishes from an ornamental aquaculture facility: the case of topmouth gudgeon Pseudorasbora parva. Journal of Fish Biology 65, 326-227.

Blanc G. (1997) Introduction of pathogens in European aquatic ecosystems: attempt of evaluation and realities. Bulletin Français de la Pêche et de la Pisciculture 344-345, 37-56. 
Britton J.R., Cucherousset J., Davies G.D., Godard M.J. \& Copp G.H. (2010) Nonnative fishes and climate change: predicting species responses to warming temperatures in a temperate region. Freshwater Biology 55, 1130-1141.

Clavero M. (2011) Assessing the risk of freshwater fish introductions into the Iberian Peninsula. Freshwater Biology 56, 2145-2155.

Copp G.H., Bianco P.G., Bogutskaya N., Erős T., Falka I., Ferreira M.T., Fox M.G., Freyhof J., Gozlan R.E., Grabowska J., Kováč V., Moreno-Amich R., Naseka A.M., Peňáz M., Povž M., Przybylski M., Robillard M., Russell I.C., Stakènas S., Šumer S., Vila-Gispert A. \& Wiesner C. (2005) To be, or not to be, a non-native freshwater fish? Journal of Applied Ichthyology 21, 242-262.

Copp G.H., Britton J.R., Cucherousset J., García-Berthou E., Kirk R., Peeler E.J. \& Stakènas S. (2009) Voracious invader or benign feline? A review of the environmental biology of European catfish Silurus glanis in its native and introduced range. Fish \& Fisheries 10, 252-282.

Copp G.H., Britton J.R., Jeney G., Joly J-P., Gherardi F., Gollasch S., Gozlan R.E., Jones G., MacLeod A., Midtlyng P.J., Moissec L., Nunn A.D., Occhipinti-Ambrogi A., Oidtmann B., Olenin S., Peeler E.J., Russell I.C., Savini D., Tricarico E. \& Thrush M. (2008). Risk assessment protocols and decision making tools for use of alien species in aquaculture and stock enhancement. Report to the European Commission, Project no.: 044142 (IMPASSE - Environmental impacts of alien species in aquaculture) for Coordination Action Priority FP6 2005-SSP-5A, Sustainable Management of Europe's Natural Resources. 84 pp. (http://www.cefas.defra.gov.uk/media/437410/impasse_44142_d3-2.pdf; last accessed 16/12/2013)

Copp G.H. Russell I.C., Peeler E.J., Gherardi F., Tricarico E., MacLeod A., Cowx I.C., Nunn A.D., Occhipinti Ambrogi A., Savini D., Mumford J. \& Britton J.R. (this issue) The European Non-native Species in Aquaculture Risk Analysis Scheme (ENSARS) - a summary of assessment protocols and decision making tools for use of alien species in aquaculture and stock enhancement. Fisheries Management \& Ecology (this issue)

EPPO (2009) Decision support system for plant pest risk analysis. European and Mediterranean Plant Protection Organization, Paris $35 \mathrm{pp}$. (http://archives.eppo.org/EPPOStandards/PM5_PRA/PRA_scheme_2009.doc; last accessed 16/12/2013).

EPPO (2011) Decision-support scheme for q uarantine pests. Paris: European and Mediterranean Plant Protection Organization, $54 \mathrm{pp}$. (http://archives.eppo.int/EPPOStandards/pra.htm; last accessed 16/12/2013)

Essl F., Dullinger S., Rabitsch W., Hulme P.E., Hülber K., Jarosik V., Kleinbauer I., Krausmann F., Kühn I., Nentwig W., Vila M., Genovesi P., Gherardi F., DesprezLoustau M.L., Roques A. \& Pysek P. (2011). Socioeconomic legacy yields an invasion debt. Proceedings of the National Academy of Science 108 (1), 203207.

European Commission (2007) Commission Regulation (EC) No 708/2007 concerning use of alien and locally absent species in aquaculture. Official Journal of the European Union (28.6.2007) L 168/1.

European Commission (2008) Commission Regulation (EC) No 506/2008 of 6 June 2008 amending Annex IV to Council Regulation (EC) No 708/2007 concerning use of alien and locally absent species in aquaculture. Official Journal of the European Union (7.6.2008) L 149/36

Fisheries and Aquaculture Department, Food and Agriculture Organization of the United Nations (FAO). Accessed on 17/02/2013. (http://www.fao.org/fishery/culturedspecies/en; last accessed 16/12/2013)

Gallien L., Münkemüller T., Albert C.H., Boulangeat I. \& Thuiller W. (2010) Predicting potential distributions of invasive species: where to go from here ?. Biodiversity Review 16, 331-342. 
Gherardi F. \& Acquistapace P. (2007) Invasive crayfish in Europe: the impact of Procambarus clarkii on the littoral community of a Mediterranean lake. Freshwater Biology 52, 1249-1259.

Gherardi F., Baldaccini G.N., Barbaresi S., Ercolini P., De Luise G., Mazzoni D. \& Mori M. (1999) The situation in Italy. In: F. Gherardi \& D.M. Holdich (eds) Crayfish in Europe as Alien Species - How to Make the Best of a Bad Situation? Rotterdam: AA Balkema, pp. 107-128.

Ghittino C., Latini M., Agnetti F., Panzieri C., Lauro L., Ciappelloni R. \& Petracca G. (2003) Emerging pathologies in aquaculture: effects on production and food safety. Veterinary Research Communications 27, 471-479.

Goulletquer P. \& Héral, M. (1997) Marine molluscan production trends in France: from fisheries to aquaculture. In: C. McKenzie, V. Burrell, A. Rosenfield, W. Hobart (eds). The history, present condition, and future of the molluscan fisheries of North and Central America and Europe. 3, 137-164.

Lim L.H.S., Timofeeva T.A. \& Gibson D.I. (2001) Dactylogyridean monogeneans of the siluriform fishes of the Old World. Systematic Parasitology 50, 159-197.

Lorincz M., Dan A., Lang M., Csaba G., Toth A.G., Szekely C., Csagola A. \& Tuboly T. (2012) Novel circovirus in European catfish (Silurus glanis). Archives of Virology 157, 1173-1176.

McMahon T.A. Brannelly L.A., Chatfield M.W.H., Johnson P.T.J., Joseph M.B., McKenzie V.J., Richards-Zawacki C.L., Venesky M.D. \& Rohr J.R. (2013) Chytrid fungus Batrachochytrium dendrobatidis has nonamphibian hosts and releases chemicals that cause pathology in the absence of infection. Proceedings of the National Academy of Science 110, 210-215.

Mihálik J. (1982) Der Wels Silurus glanis. A. Wittenberg: Ziemsen Verlag, 71 pp.

Mumford J.D., Booy O., Baker R.H.A., Rees M., Copp G.H., Black K., Holt J., Leach A.W. \& Hartley M. (2010) Non-native species risk assessment in Great Britain. In: What makes an alien invasive? Risk and policy responses. Aspects of Applied Biology, 104. Association of Applied Biologists, pp. 49-54.

Narscius A., Olenin S., Zaiko A. \& Minchin D. (2012) Biological invasion impact assessment system: from idea to implementation. Ecological Informatics 7, 4651.

Nunan L.M., Poulos B.T. \& Lightner D.V. (1998) The detection of white spot syndrome virus (WSSV) and yellow head virus (YHV) in imported commodity shrimp. Aquaculture 169, 19-30.

Olenin S., Didžiulis V., Ovčarenko I., Olenina I., Nunn A.D. \& Cowx, I.G. (2008) Review of introductions of aquatic species in Europe. Report to the European Commission, Project no.: 044142 (IMPASSE - Environmental impacts of alien species in aquaculture) for Coordination Action Priority FP6 2005-SSP-5A, Sustainable Management of Europe's Natural Resources. 41 pp. http://www2.hull.ac.uk/science/pdf/IMPASSE_44142_D1-4.pdf; last accessed 16/12/2013)

Onikura N., Nakajima J., Inui R., Mizutani H., Kobayakawa M., Fukuda S. \& Mukai T. (2011) Evaluating the potential of invasion by non-native freshwater fishes in northern Kyushu Island, Japan, using the Fish Invasiveness Scoring Kit. Ichthyological Research 58, 382-387.

Peeler E., Oidtmann B., Midtlyng P., Miossec L. \& Gozlan R. (2010) Non-native aquatic animals introductions have driven disease emergence in Europe. Biological Invasions 13, 1291-1303.

Puntila R., Vilizzi L., Lehtiniemi M. \& Copp G.H. (2013) First application of FISK, the Freshwater Fish Invasiveness Screening Kit, in Northern Europe: example of Southern Finland. Risk Analysis 33, 1397-1403.

Reading A.J., Britton J.R., Davies G.D., Shinn A.P. \& Williams C.F. (2012) Introduction and spread of non-native parasites with Silurus glanis L. (Teleostei: Siluridae) in UK fisheries. Journal of Helminthology 86, 510-513.

Secretariat of the Convention on Biological Diversity (2004). Solutions for sustainable mariculture - avoiding the adverse effects of mariculture on Biological diversity. 
Report of the Ad hoc Technical Expert Group on Mariculture - CBD Technical Series $\mathrm{N}^{\circ} 12,52 \mathrm{pp}$.

Tarkan A.S., Ekmekçi G., Vilizzi L. \& Copp G.H. (2014) Risk screening of non-native freshwater fishes at the frontier between Asia and Europe: first application in Turkey of the Fish Invasiveness Screening Kit (FISK). Journal of Applied Ichthyology (doi: 10.1111/jai.12389)

Tricarico E., Vilizzi L., Gherardi F. \& Copp G.H. (2009) Calibration of FI-ISK, an invasiveness screening tool for non-native freshwater invertebrates. Risk Analysis 30, 285-292.

Troca D.F.A. \& Vieira J.P. (2012) Potential invasive non-native fish farmed in the coastal region of Rio Grande Do Sul, Brazil. Boletim do Instituto de Pesca do Estado de Sao Paulo 38, 109-120.

Vilizzi L. \& Copp G.H. (2013) Application of FISK, an invasive-ness screening tool for non-native freshwater fishes, in the Murray-Darling Basin (south-eastern Australia). Risk Analysis 33, 1432-1440.

Weber M.J. \& Brown M.L. (2009) Effects of common carp on aquatic ecosystems 80 years after 'Carp as a dominant': Ecological insights for fisheries management. Reviews in Fisheries Science 17, 524-537.

\section{Tables}

\begin{tabular}{|c|c|c|c|c|c|c|c|c|}
\hline Species name & Common name & Authority & $\begin{array}{l}\text { Risk } \\
\text { category }\end{array}$ & \multicolumn{5}{|c|}{ Mean scores } \\
\hline Acipenser baeri $(*)$ & Siberian sturgeon & Brandt, 1869 & Medium & $1.6(1.2)$ & $2.4(1.4)$ & $1.2(1.4)$ & $2.0(1.0)$ & $0.7(1.1)$ \\
\hline $\begin{array}{l}\text { Acipenser gueldenstaedtii } \\
\left({ }^{*}\right)\end{array}$ & Russian sturgeon & $\begin{array}{l}\text { Brandt \& Ratzeburg, } \\
1833\end{array}$ & Mod. low & $1.4(1.2)$ & $1.3(1.5)$ & $1.2(1.3)$ & $1.8(1.0)$ & $1.2(1.2)$ \\
\hline Acipenser nudiventris (*) & $\begin{array}{l}\text { Fringebarbel } \\
\text { sturgeon }\end{array}$ & Lovetsky, 1828 & Mod. low & $0.9(1.1)$ & $0.2(1.0)$ & $1.5(1.2)$ & $1.0(1.0)$ & $0.9(1.1)$ \\
\hline Clarias gariepinus & African catfish & (Burchell, 1822) & Medium & $2.4(1.5)$ & $3.2(1.8)$ & $2.1(1.6)$ & $2.5(1.0)$ & $2.1(1.4)$ \\
\hline Coregonus peled & Northern whitefish & (Gmelin, 1789) & Mod. low & $1.2(1.4)$ & $1.2(1.8)$ & $1.5(1.6)$ & $1.5(1.0)$ & $0.7(1.2)$ \\
\hline Crassostrea gigas & Pacific cupped oyster & Thunberg, 1793 & Medium & $2.2(2.4)$ & $2.7(3.0)$ & $2.0(2.5)$ & $2.0(1.8)$ & $2.2(2.2)$ \\
\hline Ctenopharyngodon idella & Grass carp & (Valenciennes, 1844) & Medium & $2.1(1.5)$ & $1.8(1.8)$ & $2.4(1.6)$ & $2.3(1.3)$ & $1.9(1.5)$ \\
\hline Cyprinus carpio & Common carp & L., 1758 & Mod. high & $3.0(2.7)$ & $3.0(3.0)$ & $3.5(2.7)$ & $3.3(3.0)$ & $2.4(2.2)$ \\
\hline Huso huso $(*)$ & Beluga sturgeon & (L., 1758) & Mod. low & $1.0(1.1)$ & $1.0(1.0)$ & $1.2(1.2)$ & $1.0(1.0)$ & $0.8(1.1)$ \\
\hline $\begin{array}{l}\text { Hypophthalmichthys } \\
\text { molitrix }\end{array}$ & Silver carp & (Valenciennes, 1844) & Medium & $2.2(1.5)$ & $2.3(2.0)$ & $2.1(1.6)$ & $2.3(1.0)$ & $1.9(1.4)$ \\
\hline $\begin{array}{l}\text { Hypophthalmichthys } \\
\text { nobilis }\end{array}$ & Bighead carp & (Richardson, 1845) & Medium & $2.2(1.5)$ & $2.3(2.0)$ & $2.2(1.6)$ & $2.5(1.0)$ & $1.9(1.4)$ \\
\hline Ictalunus punctatus & Channel catfish & (Rafinesque, 1818) & Mod. low & $1.2(1.2)$ & $1.5(1.2)$ & $1.0(1.5)$ & $1.0(1.0)$ & $1.1(1.1)$ \\
\hline Sander lucioperca & Pikeperch & (L., 1758) & Medium & $2.1(1.5)$ & $2.0(2.0)$ & $2.5(1.8)$ & $2.5(1.3)$ & $1.6(0.8)$ \\
\hline Silurus glanis & European catfish & (L., 1758) & Medium & $1.8(1.4)$ & $2.4(2.0)$ & $1.9(1.6)$ & $2.3(1.0)$ & $0.8(1.2)$ \\
\hline \multicolumn{9}{|l|}{ Non-Annex IV } \\
\hline Procambarus clarkii & Red swamp crayfish & Girard, 1852 & Mod. high & $3.0(2.4)$ & $2.7(1.3)$ & $2.7(2.8)$ & $3.5(3.0)$ & $3.0(2.5)$ \\
\hline
\end{tabular}

\footnotetext{
* And hybrids thereof.
} 
Table 2. European catfish Silurus glanis as case study of species included in Part A of Annex IV of the CR No 708/2007, plus red swamp crayfish Procambarus clarkii as a non-Annex IV species for comparison. See Table 1 for risk category definitions

\begin{tabular}{|c|c|c|c|c|c|c|}
\hline \multirow{2}{*}{ Module/Species } & \multirow{2}{*}{ Risk category } & \multirow{2}{*}{ Overall mean } & \multicolumn{4}{|c|}{ Mean scores for specified module sections } \\
\hline & & & Introduction & Establishment & Dispersal & Impact \\
\hline \multicolumn{7}{|l|}{ (a) Infectious Agent } \\
\hline Silurus glanis & Moderately low & $1.5(1.8)$ & $1.8(1.9)$ & $2.3(2.5)$ & $1.4(0.8)$ & $0.6(1.9)$ \\
\hline \multirow[t]{2}{*}{ Procambarus clarkii } & Medium & $2.0(2.0)$ & $1.4(1.8)$ & $2.3(2.4)$ & $2.9(2.2)$ & $1.5(1.6)$ \\
\hline & & & Release of target organism & Release of non-target organism & & \\
\hline \multicolumn{7}{|l|}{ (b) Facility } \\
\hline Silurus glanis & Medium & $2.3(1.9)$ & $2.2(2.0)$ & $2.4(1.8)$ & & \\
\hline \multirow[t]{2}{*}{ Procambarus clarkii } & Medium & $2.4(0.0)$ & $2.3(0.0)$ & $2.4(0.0)$ & & \\
\hline & & & Import & Farming & Destination use & \\
\hline \multicolumn{7}{|l|}{ (c) Pathway } \\
\hline Silurus glanis & Moderately high & $2.5(2.3)$ & $2.3(2.0)$ & $2.3(1.7)$ & $2.8(3.0)$ & \\
\hline \multirow[t]{2}{*}{ Procambarus clarkii } & Medium & $2.1(1.5)$ & $1.9(1.1)$ & $2.3(1.7)$ & $2.0(1.8)$ & \\
\hline & & & Market impacts & Eradication costs & & \\
\hline \multicolumn{7}{|l|}{ (d) Socio-economic } \\
\hline Silurus glanis & Moderately low & $1.5(2.1)$ & $0.9(2.0)$ & $1.8(2.1)$ & & \\
\hline Procambarus clarkii & Medium & $1.9(1.6)$ & $2.6(2.1)$ & $1.2(1.0)$ & & \\
\hline
\end{tabular}

Values are mean scores for the sections of the (a) Infectious Agent, (b) Facility, (c) Pathway and (d) Socio-economic modules in the ENSARS (see Fig. 1 in Copp et al. 2014). The overall mean score for the module and its corresponding risk category are also shown. The value in parentheses is the confidence level. Risk categorisation, ranges for scores and confidence levels are given in Table 1. Risk categories as given in Table 1. 